\title{
MATERNAL SATISFACTION WITH SPINAL ANAESTHESIA FOR CAESAREAN DELIVERY AT DELHI GOVERNMENT HOSPITALS
}

\author{
Sumeet Chugh', Neetu Chaudhary2, Alpana Chugh ${ }^{3}$
}

1Specialist, Department of Anaesthesia and Intensive Care, Dr. BS Ambedkar Medical College and Hospital, Rohini, Delhi, India. ${ }^{2}$ Specialist, Department of Anaesthesia and Intensive Care, Dr. BS Ambedkar Medical College and Hospital, Rohini, Delhi, India. 3Specialist, Department of Medicine, Dr. Ram Manohar Lohia PGIMER and Hospital, Delhi, India.

ABSTRACT
BACKGROUND
The fulfilment of expectations, abolition of pain and communication are the most important determinants of the postpartum
evaluation of childbirth after caesarean delivery.
Aims and Objectives- To determine patients' perspective regarding spinal anaesthesia, their level of satisfaction and the factors of
dissatisfaction during caesarean deliveries at Delhi Government Hospital, from October 2017 to August 2018.
dissatisfaction during caesarean deliveries at Delhi Government Hospital, from October 2017 to August 2018.

\section{MATERIALS AND METHODS}

The study was designed as a cross-sectional survey. It was carried out in more than 300 bedded, tertiary care Delhi Government Hospital postnatal wards. Data was captured electronically using SPSS and analysis done using SPSS version 17. Univariate analysis was used to extract simple frequencies and the data was presented graphically. A five-point Likert scale was used to measure maternal satisfaction and various inferential statistics were used to assess association. The study was conducted from October 2017 to August 2018.

\section{RESULTS}

346 post caesarean delivery women were interviewed. The satisfaction with pain control was $89.5 \%$. $92.2 \%$ of the women were satisfied with their involvement in decision making while $94.8 \%$ were satisfied with the level of communication with their anaesthesia providers. $95.1 \%$ of the women had their expectations for delivery met. The satisfaction with the choice of spinal anaesthesia for caesarean delivery was $80 \%$. The overall satisfaction with childbirth was $95.3 \%$.

\section{CONCLUSION}

Those who experienced a poor neonatal outcome were 6.8 times more likely to be dissatisfied. The cadre of anaesthetist, marital status of parturient and number of prior caesarean deliveries had no influence on maternal satisfaction.

\section{KEY WORDS}

Spinal, Satisfaction, Caesarean, Likert Scale.

HOW TO CITE THIS ARTICLE: Chugh S, Chaudhary N, Chugh A. Maternal satisfaction with spinal anaesthesia for caesarean delivery at Delhi government hospitals. J. Evolution Med. Dent. Sci. 2019;8(08):517-521, DOI: 10.14260/jemds/2019/114

\section{BACKGROUND}

Access to healthcare is a fundamental and inalienable right. Various endpoints have been used in the past for monitoring improvements in service delivery. Smith and colleagues have proposed a '4 corner value compass' to guide quality of healthcare data collection. ${ }^{1}$ The 'compass corners' represent the 4 types of data needed to meet healthcare customer expectations and are-

\section{Patient Satisfaction}

Patient satisfaction is defined as a positive evaluation of the hospital experience. Higher patient satisfaction scores were seen to be associated with better outcomes and reduction in mortality. ${ }^{2}$

'Financial or Other Competing Interest': None.

Submission 10-12-2018, Peer Review 07-02-2019,

Acceptance 14-02-2019, Published 25-02-2019.

Corresponding Author:

Dr. Neetu Chaduhary,

House No. 109,

Navyug Apartments,

Sector-9, Rohini-110085, Delhi, India.

E-mail: dr.neetu.hrc@gmail.com

DOI: $10.14260 /$ jemds/2019/114

\section{(c) $($ ) $\ominus$}

\section{Improved Functional Status}

Functional status describes the capacity to undertake a wide range of tasks of daily living. It has been shown that hospitals with higher staff to patient ratio and lower staff turnover have higher degrees of functional improvement in patients. ${ }^{3}$

\section{Appropriate Clinical Outcomes \\ ${ }^{4}$ Measurement of health outcomes implies measuring health status before an intervention is carried out, measuring the intervention, measuring health status again and then relating the change to the intervention.}

\begin{abstract}
Appropriate Costs
Bupivacaine is the most commonly used local anaesthetic for spinal anaesthesia. It's S-enantiomer Levobupivacaine is also widely used. Lidocaine has been used in the past, but its use is no longer recommended due to the risks of cauda equina syndrome and transient neurological symptoms (TNS). 2

To improve the spinal anaesthetic efficacy, adjuvants from different pharmacological classes of drugs are used to enhance and prolong analgesia, to lower dose requirements, and to reduce dose- dependent side effects.

Opioids have attained an integral role as a spinal anaesthetic adjuvant. They are often administered in combination with local anaesthetics to enhance pain relief.
\end{abstract}




\section{Benefits of spinal anaesthesia include}

1. Easy to perform.

2. Reliable.

3. Provides excellent operating conditions for the surgeon.

4. Less costly compared to general anaesthesia.

5. Normal gastrointestinal function returns faster with spinal anaesthesia compared to general anaesthesia.

6. Patient maintains a patent airway.

7. A decrease in pulmonary complications compared to general anaesthesia.

8. Decreased incidence of deep vein thrombosis and pulmonary emboli formation compared to general anaesthesia.

9. It is an excellent technique to use in the elderly patient that may not tolerate a general anaesthetic.

\section{Disadvantages include the following}

1. Risk of failure even in skilled hands. One should always be prepared to induce general Anaesthesia.

2. Alteration in the patient's haemodynamics with risk of severe hypotension. It is essential to place. The spinal block in the operating room, while monitoring the patient's ECG, blood pressure, and Pulse oximetry. Resuscitation medications should be available.

3. The operation could outlast the spinal anaesthetic Alternative plans (i.e. general anaesthesia) should be prepared in advance.

4. Risk of complications such as post dural puncture headache and systemic toxicity from the local anaesthetic.

\section{Objective}

To determine patients' perspective regarding spinal anesthesia, their level of satisfaction and the factors of dissatisfaction during caesarean deliveries at Delhi Government Hospital, Ethiopia from October 2017 to August 2018.

\section{MATERIALS AND METHODS}

The study was designed as a cross-sectional survey. Interviews were conducted by the principal investigator and data collected in a standardized questionnaire. The study site was the Delhi Government Hospital's general postnatal wards. All the Hospitals were more than 300 bedded, Delhi Government Hospitals, with two to three general postnatal wards. Between 4000-4600 caesarean sections are performed every year at the hospitals. As the duration of the study was 1 year, the sample size was taken for convenience. Permission was sought from the Hospital's Ethics and Research Committee before undertaking the study. The study was conducted from October 2017 to August 2018.

\section{Study Population}

Parturients who had delivered via caesarean section through the spinal anaesthetic technique and who had not completed 24 hours from the onset of anaesthesia.

\section{Inclusion Criteria}

1. Parturients who had undergone caesarean delivery through the spinal anaesthetic technique.
2. Parturients for whom less than 24 hours had elapsed from the time of delivery.

3. Both elective and emergency cases of caesarean delivery via the spinal anaesthetic technique.

4. Parturients who had consented to participating in the study.

\section{Exclusion Criteria}

1. Non-consenting patients.

2. Parturients who were unable to adequately communicate with the principal investigator due to Illness, insurmountable language barrier or any other reason.

\section{Statistical Analysis}

The consecutive sampling technique was used. Data was collected using a pre-tested questionnaire. During data collection the principal investigator visited the wards, explained the study to the participants and then assisted the participants to fill the questionnaires. The data collected was quantitative. This data was captured electronically, and analysis done using SPSS version 17. To describe the study population univariate analysis was used to extract simple frequencies and the data presented graphically. A fivepoint Likert scale 5 was used to measure patients' satisfaction and various inferential statistics were derived to assess association. Chi square test was applied to compare normally distributed numerical variables between groups p-value $\leq$ 0.06 was considered for statistically significant

\section{RESULTS}

A total of 347 questionnaires were filled. Only one of the 347 questionnaires was spoilt, representing $99.7 \%$ rate of returns. The study was designed as a prospective crosssectional survey.

\section{Age}

The age of the respondents ranged from $17-45$ years. The mean age was $28.11 \pm 5.1$ years.

There was a high level of maternal satisfaction with intra operative pain control (89.5\%)

The level of satisfaction with both communication and explanations given for spinal anaesthesia were high $(94.8 \%$ and $91.1 \%$, respectively)

The level of satisfaction with involvement of the respondents in decision making was high (92.2\%) A large majority of respondents felt that their expectations for caesarean delivery were fulfilled. (95.1\%). Satisfaction with spinal anaesthetic technique was good and stood at $80 \% 6$. The overall satisfaction with the birthing experience was high (95.3\%). Mothers whose neonates died were more likely to be dissatisfied compared to mothers whose neonates were alive and well. Respondents whose neonates had a poor outcome (i.e. died) were 6.8 times more likely to be dissatisfied with spinal anaesthesia for caesarean delivery.

Seven out of the 345 deliveries $(0.2 \%)$ resulted in death of the newborn. $13.5 \%$ of the deliveries resulted in admission of the newborns to the newborn unit. 
Maternal Satisfaction with Pain Control

\begin{tabular}{|c|c|}
\hline & Percent (\%) \\
\hline Very Dissatisfied & .9 \\
\hline Dissatisfied & 2.6 \\
\hline Seither Satisfied nor Dissatisfied & 7.0 \\
\hline Sery Satisfied & 20.9 \\
\hline Total Table 1. Level of Satisfaction with Pain Control & 68.6 \\
\hline \multicolumn{2}{|c|}{} \\
\hline
\end{tabular}

89.5\% of respondents were satisfied with the level of pain control during caesarean delivery.

Satisfaction with Involvement in Decision Making During Spinal Anaesthesia

\begin{tabular}{|c|c|}
\hline & Percent (\%) \\
\hline Very Dissatisfied & 1.7 \\
\hline Dissatisfied & 1.4 \\
\hline Seither Satisfied nor Dissatisfied & 4.6 \\
\hline Satisfied & 23.4 \\
\hline Very Satisfied & 68.8 \\
\hline Total & $\mathbf{1 0 0 . 0}$ \\
\hline Table 2. Maternal Satisfaction with Involvement in Decision Making During Spinal Anaesthesia \\
\hline
\end{tabular}

$92.2 \%$ of respondents were satisfied with their involvement in decision making during spinal anaesthesia for caesarean delivery.

\begin{tabular}{|c|c|c|c|c|c|}
\hline & $\begin{array}{c}\text { Very Dissatisfied } \\
(\mathbf{\% )}\end{array}$ & $\begin{array}{c}\text { Dissatisfied } \\
(\%)\end{array}$ & $\begin{array}{c}\text { Neither Satisfied Nor } \\
\text { Dissatisfied (\%) }\end{array}$ & $\begin{array}{c}\text { Satisfied } \\
\text { (\%) }\end{array}$ & $\begin{array}{c}\text { Very } \\
\text { Satisfied (\%) }\end{array}$ \\
\hline $\begin{array}{c}\text { Level of Communication from The } \\
\text { Anesthesia Provider }\end{array}$ & .3 & .6 & 4.3 & 13.3 & 81.5 \\
\hline $\begin{array}{c}\text { The Amount of Explanation Received } \\
\text { from Anaesthesia Practitioners During } \\
\text { Birth }\end{array}$ & .9 & 1.4 & 6.6 & 13.9 & 77.2 \\
\hline \multicolumn{2}{|r|}{ Table 3. Communication and Explanations by The Anaesthesia Provider } \\
\hline
\end{tabular}

$94.8 \%$ of respondents were satisfied with the level of communication between them and their anaesthesia providers during their caesarean delivery.

91.1\% of the respondents were satisfied with the explanations for spinal anaesthesia given to them by the anaesthesia providers.

Demographic Variables and Their Influence on Maternal Satisfaction

We attempted to determine the influence of marital status, outcome of the baby, cadre of the anaesthetist and number of previ ous caesarean sections on maternal satisfaction. The only variable that had a significant influence on maternal satisfaction was the outcome of the baby.

(Two-by-two table chi square test, 1 d.f, $p=0.006$ )

\begin{tabular}{|c|c|c|c|c|}
\hline & & \multicolumn{2}{|c|}{ Overall satisfaction level } & \multirow{2}{*}{ p Value } \\
\hline & & Not satisfied & Satisfied & \\
\hline \multirow{5}{*}{ Marital Status } & Married & $4.4 \%$ & $95.6 \%$ & 0.696 \\
\hline & Single & $5.7 \%$ & $94.3 \%$ & \\
\hline & 0 & $3.0 \%$ & $97.0 \%$ & \\
\hline & 1 & $9.6 \%$ & $90.4 \%$ & \\
\hline & 2 & $2.2 \%$ & $97.8 \%$ & \\
\hline \multirow{2}{*}{ Number of Previous Caesarean Sections } & 3 & $.0 \%$ & $100.0 \%$ & \multirow{2}{*}{0.119} \\
\hline & 4 & $.0 \%$ & $100.0 \%$ & \\
\hline \multirow{3}{*}{ Type of Surgery } & Elective & $4.3 \%$ & $95.7 \%$ & \multirow[b]{2}{*}{0.821} \\
\hline & Emergency & $4.9 \%$ & $95.1 \%$ & \\
\hline & Alive and Well & $4.2 \%$ & $95.8 \%$ & \\
\hline \multirow{4}{*}{ Outcome of The Baby } & In Nursery & $2.2 \%$ & $97.8 \%$ & \multirow{2}{*}{0.006} \\
\hline & Died & $28.6 \%$ & $71.4 \%$ & \\
\hline & Consultant 1 & $9.5 \%$ & $90.5 \%$ & \\
\hline & Anaesthetist 2 & $4.8 \%$ & $95.2 \%$ & \\
\hline \multirow{2}{*}{ Cadre of Anaesthesiologist } & Registrar & $5.3 \%$ & $94.7 \%$ & \multirow{2}{*}{0.893} \\
\hline & P G Student & $.0 \%$ & $100.0 \%$ & \\
\hline
\end{tabular}


The only variable that had a significant influence on maternal satisfaction was the outcome of the baby. (Two-by-two table chi square test, 1 d.f, $\mathrm{p}=0.006$ )

\begin{tabular}{|c|c|c|c|c|c|}
\hline & \begin{tabular}{|c|} 
Very \\
Dissatisfied \\
$(\%)$
\end{tabular} & $\begin{array}{c}\text { Dissatisfied } \\
(\%)\end{array}$ & $\begin{array}{c}\text { Neither Satisfied } \\
\text { Nor Dissatisfied } \\
(\%)\end{array}$ & $\begin{array}{c}\text { Satisfied } \\
(\%)\end{array}$ & $\begin{array}{c}\text { Very } \\
\text { Satisfied } \\
(\%) \\
\end{array}$ \\
\hline $\begin{array}{c}\text { The Physical Care You Received from The Anaesthesia } \\
\text { Practitioner During Birth }\end{array}$ & .3 & 6 & 2.3 & 15.7 & 81.2 \\
\hline $\begin{array}{c}\text { The Technical Knowledge, Ability \& Competence of } \\
\text { Anaesthesia Practitioners During Birth }\end{array}$ & .3 & .9 & 7.5 & 22.5 & 68.8 \\
\hline $\begin{array}{c}\text { The Personal Interest and Attention Given to You by } \\
\text { Anaesthesia Practitioners During Birth }\end{array}$ & .6 & .0 & 3.2 & 13.0 & 83.2 \\
\hline The Attitude of Anaesthesia Practitioners During Birth & .3 & .3 & 3.2 & 10.7 & 85.5 \\
\hline The Satisfaction with Spinal Anesthetic Technique & 2.6 & 3.5 & 13.9 & 26.0 & 54.0 \\
\hline $\begin{array}{c}\text { The Anaesthesia Practitioner's Sensitivity to Your Needs } \\
\text { During Birth }\end{array}$ & 6 & .3 & 2.0 & 12.2 & 84.9 \\
\hline
\end{tabular}

Table 5. Other Related and Ancillary Issues

The satisfaction ratings for care received, knowledge of the anaesthesia provider, interest shown by the anaesthesia provider, general attitude of the anaesthesia provider and anaesthesia provider's sensitivity to the respondents' needs were all over $90 \%$.

The overall satisfaction with the spinal anaesthetic technique was $80 \%$.

\section{DISCUSSION}

A total of 346 respondents were interviewed. The participants in the study were comparable in terms of age, sex and demographic characteristics. The study done in our hospitals had a 24-hour time limit. Poor communication resulted in patient-doctor conflict in $8.3 \%$ of cases in one study, resulting in failure to give informed consent for delivery. ${ }^{7}$

Graham and Hundley also had similar results. ${ }^{8}$ Met expectations for childbirth is the most important determinant of maternal satisfaction. ${ }^{9}$ While each of these studies studied different factors that influenced satisfaction during caesarean delivery, their overall satisfaction ratings were similar. Other aspects of intraoperative anaesthetic care that were tested in the study all showed satisfaction scores of over $90 \%$. These included technical ability and competence of the anaesthesia provider and anaesthesia provider's sensitivity to the respondents' needs. The cadre of anaesthetist, urgency of the operation, marital status and number of prior caesarean deliveries had no influence on maternal satisfaction. It is unclear whether the dissatisfaction with spinal anaesthesia for respondents who had a poor neonatal outcome was due to blaming the anaesthetic technique itself or due to an unfavorable recall bias due to the unfavorable outcome. Future studies should be designed to determine this.

A study done in Greece to compare maternal preference of anaesthetic technique found that recovery from surgery was much faster after spinal anaesthesia compared to general anaesthesia. Spinal anaesthesia was also associated with less pain, fewer days of hospital stay and higher satisfaction scores compared to general anaesthesia. $80 \%$ of the women interviewed said they would choose spinal anaesthesia for a future caesarean section. ${ }^{10}$ A similar study carried out on antenatal mothers in Nigeria revealed most respondents preferred general anaesthesia and the commonest reason for the preference was various forms of fear about the conduct of anaesthesia. ${ }^{11}$ Maternal preference for anaesthetic technique may be influenced by various factors such as age, occupation, culture, religion, socio-economic status and level of education. While satisfaction after spinal anaesthesia is usually higher compared to general anaesthesia, this does not necessarily translate to greater maternal preference for spinal anaesthesia.12 Despite considerable research, satisfaction is still poorly defined.13 It is a multi-dimensional concept influenced by a variety of factors. ${ }^{14}$ This means that women can be satisfied with some aspects of

childbirth and dissatisfied with others. ${ }^{15}$ Porter and colleagues found that patients undergoing caesarean delivery find the most distressing factors, and by extension the factors most likely to influence their satisfaction, are of a psychological or general nature such as poor communication, fears, missing out on the birth or immediate postpartum period. ${ }^{15,16}$

Hodnett and colleagues found that factors traditionally thought to greatly influence satisfaction such as pain relief and intrapartum medical interventions were neither as obvious, nor as powerful as the psychological factors. ${ }^{15}$

Lavender and colleagues conducted a study to determine what aspects of childbirth experience women perceived as being crucial. They found that spouse's support, emotional control, pain relief and involvement in decision making were among the most important factors.17 Pain control, competence of the anaesthesia provider, quality of care received, maternal involvement in decision making and communication are important factors that determine the parturient's satisfaction with anaesthesia for caesarean delivery. Post-operative pain is highly variable between individuals and is influenced by multiple factors, including sensitivity to pain, psychological factors, age and genetics. ${ }^{18}$ despite advances in postoperative pain management, postoperative pain relief and satisfaction are still inadequate in some patients because of individual variability and limitation from side effects of analgesic drugs or techniques. Results from a study in the USA suggest that a patient has a 50 to $71 \%$ chance of experiencing moderate to severe pain after surgery. ${ }^{19}$

Caesarean delivery patients have even more compelling reasons to achieve optimal postoperative pain relief than other surgical patients. This is because they are at a higher risk for thromboembolic events, which may also be precipitated by immobility from inadequate pain control or 
excessive sedation from opioids. Moreover, these women want to ambulate, to be alert and energetic enough to care for, interact with and breastfeed their newborn.

Inadequate pain management after caesarean delivery might affect the emotional wellbeing and physical recovery of patients and affect mother-child bonding. ${ }^{20}$ High pain levels irrespective of mode of caesarean delivery affect breastfeeding and infant care. Good pain control is associated with reduced length of hospital stay and reduced consumption of self- administered analgesia. ${ }^{21}$

With these goals in mind, the analgesic of choice requires minimal transfer in breast milk, little or no effect on neonates, minimal maternal side effects and minimal or no interference with caring for the newborn or discharge from hospital.

\section{CONCLUSION}

1. Spinal anesthesia is effective in controlling pain during and immediately after caesarean delivery.

2. Maternal satisfaction with involvement in decision making for caesarean delivery Delhi Government Hospitals is high.

3. Spinal anaesthesia for caesarean delivery is associated with high levels of met expectations for Childbirth at Delhi Government Hospital.

4. Neonatal outcome is an important contributor to maternal satisfaction with caesarean delivery.

\section{Recommendations}

1. Spinal anaesthesia should be adopted in a protocol as the anaesthetic management technique of choice to be used in all caesarean deliveries unless there are specific contraindications.

2. Standardized questionnaires on patient satisfaction should be formulated to regularly assess quality of healthcare service delivery.

3. Further studies are recommended to determine maternal satisfaction after general anaesthesia and to compare it to spinal anaesthesia.

\section{REFERENCES}

[1] Smith JE, Fisher DL, Endorf-Olson JJ. Integrating patient satisfaction into performance measurement to meet improvement challenges. Jt Comm J Qual Improv 2000;26(5):277-86.

[2] Cherouny P, Federico FA, Haraden C, et al. Idealized design of perinatal care. IHI innovation series white paper, Cambridge, MA: Institute for Healthcare Improvement 2005.

[3] Spector WD, Takada HA. Characteristics of nursing homes that affect resident outcomes. J Aging \& Health 1991;3(4):427-54.

[4] Frommer S, Michael B, Rubin M, et al. The NSW health outcomes program. New South Wales Public Health Bulletin 3, 1992;(12):135.
[5] Likert R. A technique for the measurement of attitudes. Archives of Psychology 1932;22(140):5-55.

[6] Siddiqi R, Jaffri SA. Maternal satisfaction after spinal anaesthesia for caesarean deliveries. J Coll Physicians Surg (Pakistan) 2009;19(2):77-80.

[7] Lescale KB, Inglis SR, Eddleman KA, et al. Conflicts between physicians and patients in non - elective caesarean deliveries: incidence and the adequacy of informed consent. Am J Perinatol 1996;13(3):171-6.

[8] Graham WJ, Hundley V, McCheyne AL, et al. An investigation of women's involvement in the decision to deliver by caesarean section. Br J Obstet \& Gynecol 1999;106(3):213-20.

[9] Ha JF, Longnecker N. Doctor patient communication: a review. Ochsner J 2010;10(1):38-43.

[10] Fassoulaki A, Staikou C, Melemeni A, et al. Anaesthesia preference, neuraxial vs. general and outcome after caesarean section. J Obstet Gynecol 2010;30(8):81821.

[11] Bukar M, Kwari DY, Moruppa JY, et al. Anaesthesia for caesarean delivery: choice of technique among antenatal attendees in North Eastern Nigeria. J Obstetr Gynecol 2010;30(8):822-5.

[12] Slade P, MacPherson SA, Hume A, et al. Expectations, experiences and satisfaction with labour. Br J Clin Psychology 1993;32(Pt 4):469-83.

[13] Williams B. Patient satisfaction - a valid concept? Social Sciences \& Medicine 1994;38(4):509-16.

[14] Hodnett ED. Pain and women's satisfaction with the experience of childbirth: a systematic review. Am J Obstet Gynecol 2002;186(Supp Nature 5): S160-S72.

[15] Porter M, Van Teijilingen F, Yip CYL, et al. Satisfaction with caesarean section: qualitative analysis of open ended questions in a large postal survey. Birth 2007;34(2):148-54.

[16] Lavender T., Walkinshaw SA, Walton I. A prospective study of women's views of factors contributing to a positive birth experience. Midwifery 1999;15(1):40-6.

[17] Bramadat IJ, Driedger M. Satisfaction with childbirth: theories and methods of measurement. Birth 1993;20(1):22-9.

[18] Turk DC, Okifuji A. Assessment of patients' reporting of pain: an integrated perspective. Lancet 1999;353(9166):1784-8.

[19] Apfelbaum JL, Chen C, Mehta SS, et al. Postoperative pain experience: results from a national survey suggest postoperative pain continues to be undermanaged. Anesth Analg 2003;97(2):534-40.

[20] Tan EC, Lim Y, Teo YY, et al. Ethnic differences in pain perception and patient-controlled analgesia for postoperative pain. J Pain 2008;9(9):849-55 .

[21] Karlström A, Enqström-Oloffson R, Nystedt A, et al. Women's postoperative experiences before and after the introduction of spinal opioids in anaesthesia for caesarean section. J Clin Nurs 2010;19(9-10):1326-34. 